ISSN: 0213-2060

DOI: http://dx.doi.org/10.14201/shhme201533327341

\title{
LA IDENTIDAD URBANA Y LA HISTORIA SOCIAL DE LA POLÍTICA EN EL MUNDO URBANO ESPAÑOL Y PORTUGUÉS EN LA BAJA EDAD MEDIA
}

\section{Urban Identity and Social History of the Politics in the Spanish and Portuguese Urban World in the Late Middle Ages}

Jesús Ángel SOLÓRZANO TELECHEA

Depto. de Ciencias Históricas. Facultad de Filosofía y Letras. Universidad de Cantabria. Avda. de los Castros, 52.E-39005 Santander. C. e.: jesusangel.solorzano@unican.es

Recibido: 2015-04-06

Aceptado: 2015-09-28

SUMARIO: 1 Referencias bibliográficas.

En este trabajo me voy a centrar en dos obras monográficas de reciente aparición, que han supuesto un avance notable en el conocimiento de las sociedades urbanas con relación a dos tendencias de análisis historiográfico, como son la identidad y la historia social de la política en las ciudades peninsulares bajomedievales ${ }^{1}$. El primero de estos conceptos se ofreció como remedio a la crisis de las categorías sociales clásicas hace ya unos ańos y se ha revelado como una dimensión de análisis muy útil, ya que pone el acento en la construcción de los discursos, así como los valores y su representación colectiva, si bien hay que decir que ello ha provocado su alejamiento de la historia social ${ }^{2}$.

1 Monsalvo Antón, José M.a (ed.). Sociedades urbanas y culturas politicas en la Baja Edad Media castellana. Salamanca: Ediciones Universidad de Salamanca, 2013. JARA Fuente, José Antonio (coord.). Ante su identidad. La ciudad hispánica en la Baja Edad Media. Cuenca: Ediciones de la Universidad de Castilla-La Mancha, 2013.

2 Prost, Antoine. Doce lecciones sobre la historia. Madrid: Cátedra, 2001 (primera edición en francés del año 1996). 
JESÚS ÁNGEL SOLÓRZANO TELECHEA

El segundo de los parámetros -la historia social de la política- guarda una estrecha relación con las identidades, pues se halla a caballo entre lo social y lo político, y se ha presentado, igualmente, como una renovación de la historia social clásica y de las mentalidades. El objetivo de esta tendencia ha consistido, primeramente, en señalar que la progresiva institucionalización de la vida social influyó en gran medida sobre las identidades individuales y colectivas, así como en rehabilitar el papel de los actores sociales ${ }^{3}$.

En el libro coral coordinado por José María Monsalvo Antón, Sociedades urbanas y culturas politicas en la Baja Edad Media castellana, se analizan las consecuencias de las acciones colectivas de los grupos sociales sobre las ciudades y el gobierno urbano en la Castilla bajomedieval desde diversas perspectivas. La cultura política bajomedieval estaba constituida por diversos elementos, como instituciones, relaciones de poder, prácticas y discursos ideológicos, que incluían también unos códigos de conducta, formal e informal, así como unas acciones de gobierno que organizaban la vida política y caracterizaban a todo un sistema político dado en una sociedad determinada ${ }^{4}$. Todos estos elementos se encuentran en la presente obra.

En primer lugar, Juan Antonio Bonachía Hernando ha analizado la evolución del paisaje urbano, entre mediados del siglo XIII y comienzos del XVI, desde una perspectiva política, en el que cobra especial importancia la fiscalidad y el bien común, como parte de los discursos de los gobiernos urbanos. El autor comienza analizando los espacios de la esfera pública (calles, plazas, caminos, fuentes, puentes...) y las murallas en la legislación alfonsina, que relaciona con los conceptos de honra y bien común, de tal manera que la contribución económica a su construcción y mantenimiento era un deber tanto de la colectividad, como de las autoridades locales. Tras lo cual examina el desarrollo urbano castellano y concentra su atención en la construcción de las murallas y en la labor reglamentista y sancionadora de las autoridades concejiles para solventar la difícil financiación de las obras nuevas. El discurso del bien común, que se elevaba sobre los intereses particulares, sirvió para sustentar un determinado orden social y para legitimar la actuación de los gobiernos locales.

El segundo de los trabajos pertenece a José Ramón Díaz de Durana y Jon Andoni Fernández de Larrea, quienes nos acercan a un fenómeno bien extendido en todo el norte peninsular como fue la entrada de las villas de realengo en la esfera de los señoríos territoriales, que tuvo profundas consecuencias sobre los gobiernos urbanos. Si bien el papel que tuvieron los señores en la fundación de villas fue insignificante, no lo fue el movimiento de usurpación de villas de realengo desde el ascenso de la dinastía Trastámara. Los autores repasan los distintos casos en Asturias, Cantabria, Guipúzcoa y Álava; este

3 Burke, Peter. "The language of orders in Early Modern Europe». En Bush, Michael L. (ed.). Social orders and social classes in Europe since 1500: studies in social stratification. London: Longman, 1992, pp. 1-12. JANSEN, Harry. The construction of an urban past. Narrative and system in urban history. Oxford: Berg, 2001. Foronda, François y Carrasco Manchado, Ana Isabel (dirs.). El contrato político en la Corona de Castilla. Cultura y sociedad politica entre los siglos X al XVI. Madrid: Dykinson, 2008. Boucheron, Patrick y RuIZ Gómez, Francisco (coords.). Modelos culturales y normas sociales al final de la Edad Media. Cuenca: Casa de Velázquez, Ediciones de la Universidad de Castilla-La Mancha, 2009.

Sobre el origen de este concepto, véase Dumolyn, Jan. «Political communication and political power in the Middle Ages: a conceptual journey». Edad Media, 2012, vol. 13, pp. 33-55, en especial, 45-48. 
JESÚS ÁNGEL SOLÓRZANO TELECHEA

LA IDENTIDAD URBANA Y LA HISTORIA SOCIAL DE LA POLÍTICA EN EL MUNDO URBANO ESPAÑOL Y PORTUGUÉS EN LA BAJA EDAD MEDIA

último es el territorio que mejor representa el proceso, ya que, excepto Vitoria, el resto de villas pasaron a la jurisdicción señorial. En segundo lugar, los autores analizan la intromisión de la nobleza, tanto local como comarcal, en la vida política de las villas, cuya influencia se tejía por medio de las redes clientelares con instrumentos como las treguas, el patronato sobre las iglesias urbanas y el ejercicio de ciertos cargos influyentes, como los prebostes, los adelantados y merinos mayores. El traspaso de las villas de realengo a la esfera señorial conllevó el traspaso de la facultad de nombrar los oficiales concejiles y la regulación de la vida cotidiana por medio de ordenanzas, lo que provocó la resistencia de los vecinos en la segunda mitad del siglo xv. En unos casos, los señores vendieron los oficios y, en otros, llegaron a acuerdos con los vecinos. En las villas que no cayeron en el ámbito seńorial, los gobiernos urbanos estuvieron mediatizados por los bandos-linaje, lo que provocó las luchas banderizas por el poder local. Los autores afirman que la reforma municipal de los Reyes Católicos, iniciada en Vitoria en 1476 y extendida a la mayor parte de las villas del Cantábrico, trajo consigo la pacificación de las villas, si bien habría que ańadir que, en realidad, se trata de un proceso que arranca de los inicios del reinado de Juan II y que fue retomado en el último cuarto del siglo $\mathrm{XV}^{5}$.

El siguiente estudio, de Ernesto García Fernández, está centrado en el análisis de la teoría y la práctica política en las villas medievales del País Vasco. En primer lugar, de manera acertada desde nuestro punto de vista sobre esta problemática histórica, frente a la historiografía revisionista, el autor afirma que no se puede minusvalorar la existencia de conflictos entre grupos sociales contrapuestos, como eran el común y las oligarquías urbanas $^{6}$. Además, centra su estudio en un grupo escasamente estudiado en las villas del norte peninsular, como eran los vecinos de la tierra de las villas con los gobiernos locales ${ }^{7}$. Este sector de la población, por lo general marginado de los gobiernos concejiles, era muy heterogéneo. Había notables diferencias económicas y socio-jurídicas. Este grupo, al igual que hizo el común en el interior de los centros urbanos, reivindicó una política guiada por el bien común. El «colectivo aldeano» de las villas cuestionó con frecuencia las políticas de los gobiernos locales. Las quejas fueron acordadas en juntas y asambleas, donde se elegían procuradores que llevaban los memoriales de agravios ante los concejos

5 Sobre este proceso, véase Solórzano Telechea, Jesús Ángel. «Elites urbanas y construcción del poder concejil en las Cuatro Villas de la Costa de la Mar (siglos xiII-Xv)». En Arízaga Bolumburu, Beatriz y Solórzano Telechea, Jesús Ángel (eds.). Ciudades y villas portuarias del Atlántico en la Edad Media. Logrońo: Instituto de Estudios Riojanos, 2005, pp. 187-230. ÍDEM. «The politics of the urban commons in Northern Atlantic Spain in the Later Middle Ages». Urban History, 2014, vol. 41/2, pp. 83-204. ÍDEM. «Protestas del común y cambio político en las villas portuarias de la España atlántica a finales de la Edad Media». En Oliva Herrer, Hipólito R.; Challet, Vincent; Dumolyn, Jan y Carmona Ruiz, M. a Antonia (eds.). La comunidad medieval como esfera pública. Sevilla: Universidad de Sevilla, 2014, pp. 45-72.

6 Véase al respecto: Solórzano Telechea, Jesús Ángel y HaEmers, Jelle. «Los grupos populares en las ciudades de la Europa medieval: reflexiones en torno a un concepto de historia social». En SolóRZANo Telechea, Jesús Ángel; Arízaga Bolumburu, Beatriz y Haemers, Jelle (eds.). Los grupos populares en la ciudad medieval europea. Logrońo: Instituto de Estudios Riojanos, 2014, pp. 17-49. NAEgLE, Gisela y Solórzano Telechea, Jesús Ángel. «Geschlechter und Zünfte, prinçipales und común. Städtische Konflikte in Kastilien und dem spätmittelalterlichen Reich». Zeitschrift für Historische Forschung, 2014, vol. 41/4, pp. 561-618.

Véase el reciente estudio de Liddy, Christian D. «Urban Enclosure Riots: Risings of the Commons in English Towns, 1480-1525». Past and Present, 2015, vol. 226, pp. 41-77. 
JESÚS ÁNGEL SOLÓRZANO TELECHEA

y devolvían las respuestas de estos. Los discursos de ambos sectores fueron radicalmente opuestos, pues los aldeanos se presentaban actuando por el bien común y recordando lo que había sido desde «tiempos inmemoriales». Las discrepancias muchas veces acabaron en los tribunales. Las reivindicaciones cuestionaban la incorporación de las aldeas al término de la villa, la exigencia de tasas, los repartimientos extraordinarios, el deber de defensa o la asistencia a los alardes. Tras ello, el autor analiza varios casos de entradas de aldeas en los términos urbanos en el condado de Vizcaya y las provincias de Guipúzcoa y Álava. Los centros urbanos anexionaron un buen número de aldeas que vieron en la incorporación una forma de defenderse de la violencia señorial que asoló estas regiones entre mediados del siglo XIV y mediados de la centuria siguiente. Sin embargo, el final de dicha violencia abrió en estas aldeas un nuevo discurso "antiurbano» a causa de la oposición a la fiscalidad concejil. Algunos gobiernos urbanos tuvieron que llegar a acuerdos con sus aldeas en temas fiscales y electorales, aunque otros quedaron sometidos totalmente. Por otra parte, al final del proceso, hubo notables diferencias entre las provincias de Guipúzcoa y Álava con el condado de Vizcaya. Mientras en las primeras los términos jurisdiccionales de los centros urbanos crecieron, en Vizcaya se redujeron, debido a la peculiaridad institucional de la inserción de la llamada Tierra Llana. Los conflictos entre gobiernos urbanos y colectivos aldeanos argumentaron con un discurso compartido en torno al ideal del bien común, aunque sus intereses fueran opuestos.

Por su parte, el trabajo de José Antonio Jara Fuente se inscribe en su consolidada línea de investigación sobre la identidad política urbana en el centro de la Corona de Castilla. El autor analiza, partiendo del estudio de las relaciones entre la nobleza urbana y la sociedad política, los discursos ideológicos y el vocabulario político (servicio/ deservicio, bien común, amor, amistad), utilizado tanto por la ciudad de Cuenca para alcanzar el apoyo regio, como por la nobleza local. Esta ciudad hubo de hacer frente a las usurpaciones de la nobleza y a la centralización monárquica del siglo xv; aunque supo reconducir aquellas relaciones desde la subordinación a la cooperación y el respeto. La acción discursiva de Cuenca se fundamentó, en primer lugar, en el papel del monarca como representante de la comunidad política del reino, cuya actuación estaba sometida a la valoración de la misma. La noción de servicio/deservicio al rey, a la ciudad y a la comunidad se convirtió en el eje de los intereses generales, que sirvieron como patrón de medida de todas las actuaciones. Junto a este concepto, se hallaba el de bien común, equivalente al buen gobierno y a la justicia. Los cuatro conceptos -servicio, bien común, buen gobierno y justicia- constituyeron el armazón ideológico sobre los que se sustentó la legitimidad de la acciones políticas y se contribuyó a la definición de las conductas cívicas. Igualmente, Jara Fuente introduce otros conceptos del discurso, como afecçión, buena voluntad, amor, debdo, que estaban cargados no solo de un sentido afectivo, sino también político, ya que creaba una reciprocidad, que debía ser libremente respetada. En suma, la ciudad de Cuenca, como otras, supo aprovecharse de los referentes ideológicos para hacerse respetar por la nobleza y la monarquía.

El siguiente trabajo pertenece a Juan Carlos Martín Cea, quien reflexiona sobre la constitución de las plazas como espacios públicos donde se desarrollaba la convivencia en las ciudades castellanas del siglo Xv. Martín Cea, en primer lugar, afirma que estamos 
JESÚS ÁNGEL SOLÓRZANO TELECHEA

LA IDENTIDAD URBANA Y LA HISTORIA SOCIAL DE LA POLÍTICA EN EL MUNDO URBANO ESPAÑOL Y PORTUGUÉS EN LA BAJA EDAD MEDIA

ante un espacio que no seguía un patrón determinado, tal como lo demuestra la gran variedad de denominaciones que se utilizaban para referirse a ellos, como plaças, plaçuelas, plaçoletas, azogues, atrios, corros, explanadas, glorietas, etc. Uno de los elementos que más influyeron en la conformación de las plazas fue el mercado, pero afirma Martín Cea que esto no fue definitorio, sino que las autoridades buscaban que los vecinos dispusieran de un espacio común para todos. El proceso de conformación de estos espacios en públicos se encontró con diversas dificultades. En los centros urbanos de pequeño y mediano tamaño, la plaça del mercado se convirtió en la plaza pública/mayor/principal, pero en las grandes ciudades hubo varios lugares que aspiraron a esta categoría y los concejos tuvieron que desplegar sus esfuerzos para sacar adelante sus propuestas. El autor, en segundo lugar, analiza las funciones sociales de la plaza pública, entre las que destaca su dedicación mercantil, que los concejos regularon para evitar su mal uso y para proteger sus actividades, así como su función propagandística de la administración de la justicia y por acoger en su entorno la sede del regimiento. Además de esto, la plaza pública era el centro distribuidor de la información local, tanto la oficial de los pregoneros, como la de los rumores vecinales. Por último, la plaza era un espacio destinado al ocio, a las celebraciones y a las recepciones regias. Todas estas funciones, promovidas por los concejos, respondían al deseo de los gobiernos urbanos de transmitir su buen hacer, motivo por el cual promovieron las infraestructuras como fuentes y pozos, el acondicionamiento y la limpieza, el empedrado y la pavimentación. El concejo, además de imponer las ordenanzas, aspiraba a lograr un gran consenso que legitimase a los gobernantes locales. Por último, Juan Carlos Martín Cea se pregunta si no se sitúa, acaso, este espacio público en los primeros pasos hacia la Modernidad, en el sentido dado por Jürgen Habermas. En efecto, los diversos estudios sociales de los últimos años han venido a cuestionar el modelo interpretativo de Habermas sobre el surgimiento de la esfera pública burguesa en el siglo XVIII, ya que podemos rastrearlo desde algunos siglos antes ${ }^{8}$. En el esquema de Habermas el pueblo era una entidad muda y manipulable, pero la preocupación de las autoridades concejiles por las plazas públicas demuestra que estaban interesados en conformar y conocer la opinión de los habitantes de las ciudades.

El coordinador de esta monografía, José María Monsalvo Antón, analiza la ideología política, los valores y las actitudes del patriciado urbano de Salamanca entre los siglos XIII y xv. Se trata, sin duda, de una valiosísima investigación, ya que arroja luz sobre un tema escasamente documentado. En primer lugar, el autor estudia las consecuencias de la instauración del Regimiento, que trajo de una parte la diferenciación entre una elite de gobierno y el resto del estamento caballeresco y la eliminación de cualquier competencia u oposición que pudiera venir de las asambleas vecinales. El grupo dirigente era distinguido, además, por su dinero y la amplitud de su parentela. Esta elite tenía

8 Habermas, Jürgen. Historia y crítica de la opinión pública. La transformación estructural de la vida pública. Barcelona: Gustavo Gili, 1981. ÍDEm. The Structural Transformation of the Public Sphere. Cambridge: The MIT Press, 1989. El debate sobre el modelo de Habermas, vid. CrossLey, Nick y RoberTs, John Michael (eds.). After Habermas: new perspectives on the Public Sphere. Oxford: Wiley-Blackwell, 2004. Boucheron, Patrick y Offenstadt, Nicolas (eds.). L'espace public au Moyen Âge. Débats autour de Jürgen Habermas. Paris: Presses Universitaires de France, 2011. 
JESÚS ÁNGEL SOLÓRZANO TELECHEA

una clara idea de su superioridad respecto al resto del estamento y, en especial, de los no privilegiados, que se plasmaba tanto en su denominación -prinçipales-, como en la apariencia de sus viviendas. Además, tampoco dudaron en recurrir a la violencia contra el campesinado pechero para apropiarse de tierras e, incluso, de lugares, en especial, en la Tierra de Salamanca. En el ámbito rural, construyeron torres y casas fuertes, que les sirvieron para resistirse a la justicia y el orden. Tras esto, el autor estudia los conflictos entre el estamento de los caballeros, escuderos e hidalgos y la minoría patricia, que constituyó un elemento esencial para comprender la sociedad política urbana bajomedieval. En este conflicto, los caballeros no patricios necesitaron del apoyo de los pecheros para reforzar su posición frente a la política excluyente de los regidores. En este punto, Monsalvo analiza las ordenanzas y concordias sobre el gobierno local de Salamanca, que establecieron un reparto de los cargos menores entre los linajes'. Especialmente importante nos parece el hecho de que estos oficiales hubieran de elegirse sin arte e sin engaño e sin bandería, ya fuera por acuerdo de los linajes o por suertes ${ }^{10}$. Comenta Monsalvo que «apenas hay indicios de conflictos abiertos entre caballeros y pecheros» significativos. En este punto, nos parece que los acuerdos y las peticiones que se elevaron a los monarcas a lo largo del siglo XV nos ofrecen un ejemplo perfecto sobre la articulación de las críticas al sistema político por parte de los pecheros, que no siempre se expresaron de manera violenta, sino que supieron articular un discurso coherente dirigido contra las elites gobernantes, que los transformó en comunidades con intereses comunes y fueron tenidos en cuenta de manera decisiva por parte de los distintos poderes ${ }^{11}$. A continuación, el autor analiza la

9 Sobre los sistemas electorales locales en Europa, véase: NajEmy, John M. Corporatism and Consensus in Florentine Electoral Politics, 1280-1400. Chapel Hill: University of North Carolina Press, 1982. ScHNEIDeR, Reinhard y Zimmermann, Harald (dirs.). Wahlen und Wählen im Mittelalter. Sigmaringen: Thorbecke, 1990. Rigaudière, Albert. "Voter dans les villes de France au Moyen Âge (XIII-Xve s.)». Comptes-rendus des Séances de l'Académie des Inscriptions et Belles-Lettres, 2000, vol. 144/4, pp. 1439-1471. PÉnEAU, Corinne (ed.). Élections et pouvoirs politiques du VIT au XVIT siècle. Bordeaux: Éditions Bière, 2008. Gilli, Patrick. "Aux sources de l'espace politique: techniques électorales et pratiques délibératives dans les cités italiennes (XII ${ }^{\mathrm{e}}-\mathrm{XIV}^{\mathrm{e}}$ siècles)». En Boucheron y Offenstadt (eds.), L'espace public au Moyen Âge, pp. 229-247.

10 Este tipo de ordenanzas las hallamos en otros centros urbanos del norte de España, como Santander, Laredo, Deba, Vitoria y Bilbao. Vid. Solórzano Telechea, Jesús Ángel. «La aparición y consolidación de la acción política del Común en las villas portuarias del Cantábrico en la Baja Edad Media». En Gentes de mar en la ciudad atlántica medieval. Logrońo: Instituto de Estudios Riojanos, 2012, pp. 295 -312.

11 Watts, John. "The Pressure of the Public on Later Medieval Politics». En Clark, Linda and Carpenter, Christine (eds.). The Fifteenth Century IV. Political Culture in Late Medieval Britain. Woodbridge: Boydell \& Brewer, 2004, pp. 159-180. ÍDEm. The Making of Polities: Europe, 1300-1500. Cambridge: Cambridge University Press, 2009. Ormrod, W. Mark. «Murmur, clamour and noise: Voicing complaint and remedy in petitions to the English crown, c. 1300-c. 1460». En Ormrod, W. Mark; DodD, Gwilym y Musson, Anthony (eds.). Medieval Petitions: Grace and Grievance. York/Woodbridge: York Medieval Press, 2009, pp. 135-155. Liddy, Christian D. «Bill casting and political communication: A public sphere in late medieval English towns?». En Solórzano Telechea, Jesús Ángel y Arízaga Bolumburu, Beatriz (eds.). La gobernanza de la ciudad europea en la Edad Media. Logrońo: Instituto de Estudios Riojanos, 2011, pp. 447-461. Liddy, Christian D. and Haemers, Jelle. "Popular politics in the late medieval town: York and Bruges». English Historical Review, 2013, vol. 128, pp. 771-805. NiETo Soria, José Manuel. «Three models of monarchy in fifteenth-century Castile». En Hoppenbrouwers, Peter; Janse, Antheun y Stein, Robert (eds.). Power and Persuasion. Essays on the Art of State Building in Honour of W. P. Blockmans. Turnhout: Brepols, 2010, pp. 85-102. 
JESÚS ÁNGEL SOLÓRZANO TELECHEA

LA IDENTIDAD URBANA Y LA HISTORIA SOCIAL DE LA POLÍTICA EN EL MUNDO URBANO ESPAÑOL Y PORTUGUÉS EN LA BAJA EDAD MEDIA

violencia de bandos y la intromisión del conde de Alba en la vida política de Salamanca. El conflicto dinástico castellano conllevó el alineamiento de los bandos con las fuerzas foráneas del reino, lo que ahondó más el conflicto interno. Con todo, en el último cuarto del siglo XV se asiste a las treguas y concordias privadas con el objetivo de pacificar Salamanca, que propiciaron la destrucción de los bandos, según el autor, ya que los intereses particulares se impusieron a los de los bandos-linaje. En suma, el autor aporta una rica reflexión sobre la acción política de las elites urbanas castellanas, que era el resultado de un complejo juego de intereses y estrategias políticas.

Esta monografía se cierra con el trabajo de Soledad Tena García sobre la conflictividad existente en San Sebastián a finales de la Edad Media, motivada por el deseo de controlar los cargos concejiles y los asuntos económicos. Estos últimos estaban relacionados, principalmente, con las actividades ligadas al mar, nos explica la autora, lo que originó el desarrollo de tres cofradías de oficios, que además defendieron los intereses del común ${ }^{12}$. Estas cofradías fueron capitalizadas, desde sus inicios, por las elites villanas, precisamente un sector social que estaba excluido del poder político urbano, por lo que las organizaciones de oficios se convirtieron en un instrumento para hacer oír su voz. Los conflictos se iniciaron con el reinado de Enrique IV y llegaron a su punto álgido con los Reyes Católicos. Las autoridades urbanas regularon todo tipo de actuación que fuera en contra de sus intereses, prohibieron la formación de ligas y regularon las actividades económicas por medio de ordenanzas concejiles; muchos de esos aspectos habían sido controlados exclusivamente por las cofradías con anterioridad. Otro ámbito de conflictividad, nos informa la autora, se abrió por el aprovechamiento del puerto de Pasajes y las zonas adyacentes, ya que los poderosos defendían el control absoluto de las actividades portuarias y el cobro de aranceles y tasas de todo tipo, pero estos intereses colisionaban con los de los trabajadores de los oficios del mar, que necesitaban un puerto que fuera cuanto más activo mejor.

La segunda obra que nos ocupa, titulada Ante su identidad. La ciudad hispánica en la Baja Edad Media, ha sido coordinada por José Antonio Jara Fuente y gira en torno a la identidad urbana en España y Portugal en la Baja Edad Media. Las tendencias historiográficas de la identidad urbana tienen su génesis en el intento de dar una respuesta a la crisis de los estudios sociológicos, comprendidos entre el final de la Primera Guerra Mundial y los años setenta del pasado siglo, que habían transmitido una imagen ordenada del mundo social, en el que existían modelos de clasificación de los grupos sociales

12 En este sentido, véase: KIESER, A. «Organizacional, Institucional and Societal Evolution: Medieval Craft Guilds and the Genesis of Formal Organizations». Administrative Science Quarterly, 1989, vol. 34/4, pp. 540-564; Monsalvo AnTón, José María. «Solidaridades de oficio y estructuras de poder en las ciudades castellanas de la Meseta durante los siglos XIII al XV (aproximación al papel político del corporativismo artesanal)». En VACA, Ángel (ed.). El trabajo en la Historia. Salamanca: Ediciones Universidad de Salamanca, 1996, pp. 39-90; Trio, Paul. «Les confréries comme expression de solidarité et de conscience urbaine aux Pays-Bas à la fin du Moyen Âge». En Brand, Hanno; Monnet, Pierre y Staub, Martial (eds.). Memoria, communitas, civitas. Memoire et conscience urbaines en Occident à la fin du Moyen Âge. Ostfildern: Thorbecke, 2003, pp. 131-141. García Fernández, Ernesto. "Las cofradías de mercaderes, mareantes y pescadores vascas en la Edad Media». En Arízaga Bolumburu y Solórzano Telechea (eds.), Ciudades y villas portuarias del Atlántico en la Edad Media, pp. 257-294. 
JESÚS ÁNGEL SOLÓRZANO TELECHEA

con base en la actividad económica. Esta perspectiva adolecía de ser muy reduccionista e, incluso, se habían creado grupos sociales ficticios con individuos que jamás habrían compartido ningún objetivo común. Si bien se partía de la situación económica para establecer los grupos sociales, Norbert Elías y Pierre Bourdieu introdujeron las diferencias culturales para poder reconocerlos, aunque mientras Bourdieu rehuía de la historicidad de los procesos, Elías defendía el supuesto de que toda realidad social únicamente puede entenderse de manera procesual, por lo que la sociología tenía que ser histórica ${ }^{13}$. De este modo, como solución a la crisis de las categorías sociales clásicas, se ofreció el concepto de identidad, que se reveló como una herramienta analítica muy útil, pues ponía el acento en la construcción de los discursos, así como los valores y su representación ${ }^{14}$. El objetivo de esta monografía reside en analizar y reconstruir la realidad urbana bajomedieval en la Península Ibérica a partir de los diferentes elementos que llevaron a construir una identidad política urbana dada ${ }^{15}$.

Tras la interesante introducción del coordinador de la obra, en la que explica el origen y propósito del libro, Adelaide Millán da Costa reflexiona sobre la aplicación del concepto de identidad a las ciudades portuguesas. La autora reflexiona, en primer lugar, sobre el concepto de identidad, que puede aludir tanto a lo que es único, como a lo que es común, así como sobre la insegura frontera que separa la identidad urbana, que percibe el investigador, de la identidad urbana construida por los gobernantes concejiles. La ciudad elegida por la autora para centrar su análisis sobre la percepción y la construcción de la identidad urbana es Coruche, una villa con representación en las cortes portuguesas, aunque en los últimos asientos de la cámara. La defensa hecha de la identidad urbana de Coruche por su clase dirigente estaba relacionada con la apropiación del estatuto jurídico, otorgado por los monarcas, para que esta villa acudiera a las cortes. La identidad urbana fue más elaborada en cuanto que la clase dirigente supo articular un discurso singular y característico a partir de lo similar con el objetivo de que este centro urbano ocupara una posición destacable en el sistema urbano.

El segundo de los trabajos pertenece a Jean Pierre Barraqué, especialista en la elaboración de los discursos políticos urbanos, quien reflexiona en su trabajo sobre la construcción de Zaragoza como capital de Aragón a lo largo de los siglos xIV y xv. En primer lugar, el autor afirma que la identidad urbana se construyó al mismo tiempo que se produjo el estrechamiento del grupo dirigente. Las reformas de los Trastámara debilitaron el destacado papel que habían ejercido las parroquias como elementos para el ejercicio y la conquista del poder urbano. La introducción de la insaculación en 1442, aunque perseguía una mayor imparcialidad en las elecciones concejiles, produjo el efecto contrario y

13 Bourdieu, Pierre. Razones prácticas. Sobre la teoría de la acción. Barcelona: Anagrama, 1997. HudDY, Leonie. «From Social to Political Identity: A Critical Examination of Social Identity Theory». Political Psychology, 2001, vol. 22/1, pp. 127-156.

${ }_{14}$ También en los últimos ańos se ha realizado una redefinición del concepto de identidad como categoría de análisis, que ha sido sustituido por el de identificación al objeto de centrar el problema no en los rasgos de caracterización, sino en las personas que realizan y participan de la identificación. Vid. BrubaKER, Rogers. Ethnicity without Groups. Cambridge: Harvard University Press, 2004, pp. 28 y ss.

15 Sobre la identidad urbana castellana y sus elementos, véase también: VAL VALDivieso, María Isabel del. «La identidad urbana al final de la Edad Media». Anales de Historia Medieval de la Europa Atlántica, 2006, vol. 1, pp. 5-28. 
JESÚS ÁNGEL SOLÓRZANO TELECHEA

LA IDENTIDAD URBANA Y LA HISTORIA SOCIAL DE LA POLÍTICA EN EL MUNDO URBANO ESPAÑOL Y PORTUGUÉS EN LA BAJA EDAD MEDIA

reforzó el clientelismo. El discurso político regio justificó el cambio en el sistema electoral por la importancia que debían darse a las capacidades y la formación de los candidatos. De este modo, en el siglo XV, desaparecieron las referencias a las parroquias como elementos identitarios. Por el contrario, las casas familiares asumieron un mayor protagonismo y se transformaron en un factor de jerarquización social. En la afirmación como capital de Zaragoza también jugaron un importante papel los edificios de gobierno laico y eclesiástico suntuosos, como el Palacio Real de la Aljafería y la Catedral, donde también se celebraban las Cortes. Igualmente, las ceremonias regias en la ciudad, tales como las entradas, las procesiones y la celebración de las victorias del rey, así como los privilegios reales ayudaron a forjar la identidad de Zaragoza como capital del reino.

Yolanda Guerrero Navarrete realiza el tercer análisis de esta obra sobre la elite urbana de Burgos. En primer lugar, la autora presenta los rasgos identitarios de grupo social y político, como la riqueza, la influencia urbana, un modo de vida y una mentalidad aristocrática. El acceso a esta elite estaba controlado por sus miembros, que establecían una carrera política a seguir tan exigente que ni tan siquiera la riqueza podía asegurarla. La incorporación al regimiento era la última etapa de aquel cursus honorum. El patriciado burgalés oficializó, desde mediados del siglo xv, un sistema de nombramiento de los cargos concejiles basado en el control absoluto de los cargos por parte de los miembros por medio del sistema de renuncias. Así, la facultad de renunciar al cargo en otro miembro del linaje consolidó un sistema cerrado en el que la elite decidía quiénes podían entrar en el círculo de poder.

Tras este interesante estudio, José Antonio Jara Fuente estudia las relaciones entre las políticas comunitarias y las identidades en la Castilla del siglo xv. En primer lugar, concluye que, a pesar de las divisiones internas de las sociedades urbanas (luchas de bandos, segregación política de una parte de la población, etc.), esto no implicó su plasmación en estructuras particulares, ni la contestación urbana a lo largo del tiempo, debido a que los «dominantes» establecieron siempre unos parámetros razonables y básicos de convivencia y seguridad. El grupo de los dominantes, además, desarrolló una acción política encaminada a generar una imagen de comunidad dada. En este punto, el autor aplica el concepto de habitus de Pierre Bourdieu para explicar la construcción de los marcos conceptuales compartidos por los vecinos, pero también generados por los dominan$\operatorname{tes}^{16}$. Las acciones de gobierno del grupo dominante se sustentaban en la defensa de los principios del bien común y en su carácter ejemplarizante. Además, el autor resta importancia a la conflictividad social e identifica las peticiones del vecindario de Cuenca al rey como conflictos intraclasistas y de baja intensidad, en modo alguno como verdaderos conflictos dominantes-dominados, ya que no implicaron al conjunto de la comunidad ${ }^{17}$.

16 Bourdieu, Pierre. Bosquejo de una teoría de la práctica. Buenos Aires: Prometeo, 2012.

17 En los últimos años, se viene analizando, asimismo, la resistencia no violenta por parte de la población urbana, ya que esta fue tan parte integral de la cultura política medieval, como también la violencia y el desorden. Véase, Ormrod, W. Mark. Political life in Late Medieval England, 1300-1450. Basingstoke: Macmillan, 1995. ÍDEM, «Murmur, clamour and noise: Voicing complaint and remedy in petitions to the English crown, c. 1300-c. 1460», pp. 135-155. Monsalvo AnTóN, José María. «Ideario sociopolítico y valores estamentales de los pecheros abulenses y salmantinos (ss. XIII-Xv)». Hispania. Revista Española de Historia, 2011, vol. LXXI, n.o 238, pp. 325-362. Dumolyn, Jan; Haemers, Jelle; Oliva Herrer, Hipólito Rafael; 
JESÚS ÁNGEL SOLÓRZANO TELECHEA

El discurso político de los dominantes estaba dirigido a su legitimación, pues se erigían en instrumentos para alcanzar el bien común y en modelos de actuación para el resto de la comunidad. El autor concluye que la construcción de la identidad de la comunidad estuvo basada en los vínculos de interés que esta mantenía con los «dominantes» y, por lo tanto, estaba edificada desde arriba con el concurso aquiescente de los dominados, lo que hubo de limitar los logros y la independencia del común ${ }^{18}$. Su propuesta, por lo tanto, enfatiza el papel de las facciones y el patronazgo, al mismo tiempo que minimiza las luchas sociales entre el grupo dominante y el dominado.

El siguiente trabajo pertenece a Maria Filomena Lopes de Barros, quien analiza la ciudad portuguesa bajomedieval con relación al discurso de las ciudades frente a las minorías religiosas, en especial, la musulmana. La autora expone que, a partir de las Cortes de Elvas de 1361, los reyes portugueses determinaron, a petición de los procuradores, que a los moros y judíos se les asignase un espacio para vivir apartados de los cristianos, tema recurrente en las siguientes reuniones de las cortes. Maria Filomena expone el deseo de las autoridades concejiles por controlar el espacio urbano y amoldar la apariencia de los centros urbanos al ideario cristiano de la Civitas Dei. Así, el concejo se afirmó sobre su espacio, lo que implicó que se inmiscuyera en los asuntos de los barrios de las minorías religiosas, ya que se derivaba de una percepción de la universitas en la que se hallaban tanto cristianos, como moros y judíos, lo que conllevó la protesta de los representantes de estas minorías. Los musulmanes también sirvieron para formar la memoria colectiva de la ciudad portuguesa bajomedieval, que reflejaba la iconografía urbana con representaciones de la derrota musulmana y de Santiago Matamoros. De este modo, tenemos un discurso urbano que incorpora a los musulmanes en su concepto de ciudad, pero que, al mismo tiempo, los excluye espacialmente de los cristianos y construye su memoria colectiva por contraposición a los enemigos derrotados.

Juan Antonio Barrio Barrio se ocupa de la construcción de la identidad de los conversos judíos en el reino de Valencia y analiza la correlación existente entre la identidad política y religiosa con la identidad propia de las comunidades urbanas. En primer lugar, el autor reflexiona sobre la construcción del marco identitario urbano cristiano desde el siglo XIII, en el que lo musulmán y lo judío difícilmente podían integrarse. Los ataques a las juderías en 1391 y a la morería de Valencia en 1455 llevaron a que estas minorías o bien se decidieran por convertirse, o bien por asentarse en el medio rural, ya que las tensiones con los cristianos hacía insostenible la convivencia. Las conversiones dieron lugar a una nueva categoría religiosa, el nuevo cristiano, que no fue comprendido por nadie y que tuvo un sinfín de dificultades para integrarse, aunque se lamenta el autor de que existe un problema de fuentes para estudiar su alcance. El autor reconstruye las fases

Challet, Vincent (eds.). The voices of the People in Late Medieval Europe. Turnhout: Brepols, 2014. Solórzano Telechea, Arízaga Bolumburu y Haemers (eds.), Los grupos populares en la ciudad medieval europea.

18 Se trata de una conclusión que ya aparece en obras anteriores de este autor. Véase, Jara FuENTE, José Antonio. «Sobre el concejo cerrado. Asamblearismo y participación política en las ciudades castellanas de la Baja Edad Media». Studia Historica. Historia Medieval, 1999, vol. 17, pp. 113-136. Jara Fuente sigue, en este punto, una larga tradición historiográfica que se remonta a los trabajos de Ottokar de 1926 y continuó con los de Sergio Bertelli, Jacques Heers y Charles Tilly, entre otros muchos. Véase Solórzano Telechea y HaEmers, «Los grupos populares en las ciudades de la Europa medieval», pp. 17-52. 
JESÚS ÁNGEL SOLÓRZANO TELECHEA

LA IDENTIDAD URBANA Y LA HISTORIA SOCIAL DE LA POLÍTICA EN EL MUNDO URBANO ESPAÑOL Y PORTUGUÉS EN LA BAJA EDAD MEDIA

por las que atravesaron los conversos valencianos, así como los espacios en los que se movieron. Existió una red de solidaridad entre las familias conversas que permitió perpetuar la identidad de grupo tras la conversión. Entre las estrategias, el autor cita la creación de cofradías y cementerios propios, el nombramiento de procuradores y el mantenimiento de su lugar de residencia. Los testimonios recogidos en los procesos inquisitoriales ofrecen un magnífico recurso para el conocimiento de los marcos de sociabilidad de la vida cotidiana y la reconstrucción de la identidad de los conversos valencianos, pero un tema que nos parece que sigue ausente en este tipo de estudios son las relaciones mantenidas entre las minorías religiosas de judíos y musulmanes ${ }^{19}$.

Flocel Sabaté i Curull se centra en la identidad de las ciudades de Cataluña en la Edad Media. En primer lugar, el autor reflexiona sobre las ventajas que ofrece el concepto de identidad para la investigación medieval, ya que el planteamiento permite definir el comportamiento social a partir de la dialéctica entre colectividad e individuo, la importancia de la memoria, los valores ideológicos y los discursos de legitimación, ámbitos que con anterioridad no eran tenidos en cuenta. Los privilegios urbanos, de los que se sentían partícipes los vecinos, formaban parte de la identidad de las ciudades y villas del principado de Cataluña y se proyectaban sobre el conjunto del territorio. La población urbana estaba convencida de que los privilegios atraían pobladores y con ello crecía la riqueza y la influencia del centro urbano. Por supuesto, la ciudad o villa debía hacer ostentación de su pujanza por medio de las mejoras urbanísticas y las celebraciones públicas. Respecto al orden social, la consolidación de los linajes en los gobiernos urbanos generó hondas tensiones, que propiciaron reformas institucionales en favor de los más pujantes, quienes desarrollaron discursos justificativos del poder concejil en torno al bien común. La sociedad urbana se veía como una plasmación de la cristiandad, por lo que la cohesión social hubo de excluir a las minorías religiosas inasimilables, como eran los musulmanes y los judíos. El poder municipal acabó influyendo en las decisiones de los monarcas aragoneses por medio de los representantes urbanos en las cortes. Según el autor, la reivindicación municipalista realizó una gran aportación al modelo de régimen político basado en el pactismo, que quedó como herencia medieval de la identidad social de los centros urbanos catalanes para los siglos posteriores.

Manuel Benítez Bolorinos analiza la identidad territorial de las comarcas del Alacantí, el Vinalopó y la Vega Baja, situadas en el sur de la provincia actual de Alicante, que se incorporaron al reino de Valencia tras los acuerdos de Torrellas y Elche a principios del siglo XIV. La identidad de estas tierras vino determinada por la distribución urbana y rural, el carácter fronterizo tanto con la corona de Castilla (frontera exterior), como con la población musulmana (frontera interior), los grupos urbanos y el reparto entre las tierras de realengo y las de señorío. A partir de su unión al reino de Valencia en 1308, se inició un proceso de construcción identitaria similar a la de los valencianos del norte por lengua, legislación y moneda, sin perder por ello cierta identidad castellana. El autor concluye que estos elementos construyeron una personalidad propia que se tradujo en la

19 IzQuierdo Benito, Ricardo. «Los conflictos socio-religiosos en las ciudades medievales castellanas». En Solórzano Telechea, Jesús Ángel y Arízaga Bolumburu, Beatriz (eds.). La convivencia en las ciudades medievales. Logrońo: Instituto de Estudios Riojanos, 2008, pp. 81-111. 
JESÚS ÁNGEL SOLÓRZANO TELECHEA

conformación de las elites urbanas y los grupos populares, si bien se trató de una identidad que evolucionó tras su incorporación a la corona de Aragón.

Charles García reflexiona en su trabajo sobre la construcción social de la identidad a partir del tiempo pasado y la memoria. Tal como argumentó Maurice Halbwachs, el primer estudioso que se dedicó al análisis de la memoria social en los años treinta del pasado siglo, no son los individuos, sino los grupos sociales los que determinan la memoria, lo que debe ser recordado ${ }^{20}$. En la Edad Media, la historia era concebida como magistra vitae y los escritores hacían uso de las auctoritates para reforzar sus opiniones, lo cual permitía combinar el pasado con el presente. El autor analiza el proceso de construcción de la memoria de los orígenes para la comunidad de Zamora, realizado por Juan Gil de Zamora en torno a 1280. Este clérigo equiparó esta ciudad con Numancia, aunque esto ya había aparecido en la Crónica de Alfonso III en su versión rotense y textos posteriores con la finalidad de dotar a Zamora de una sede episcopal antigua para convertirla en ciudad. Juan Gil de Zamora alabó, en primer lugar, el rico entorno geográfico, los orígenes antiguos, el ennoblecimiento de la etimología del nombre, elogió los actos valerosos de sus habitantes en su lucha contra los moros y enumeró las reliquias famosas que poseía. La finalidad última de la obra de Juan Gil era terminar con la disputa entre las sedes episcopales hispanas y legitimar las ansias de independencia del obispo de Zamora. La identidad urbana que creó este escritor, comenta Charles García, tuvo tal fuerza que perduró hasta la época contemporánea.

El libro se cierra con el trabajo de Hermínia Vasconcelos Vilar sobre la importancia del fenómeno religioso en la conformación de la identidad en el contexto urbano del sur de Portugal. La autora analiza el caso de Évora, reconquistada en 1165, donde los poderes religiosos y laicos compartieron un mismo reducido espacio en el centro de la antigua cerca romana. Los siglos bajomedievales asistieron a la plena implantación de las órdenes mendicantes, que vino a romper el monopolio que hasta entonces había tenido el clero secular de las catedrales y las parroquias urbanas, lo que fue origen de numerosos conflictos. El asentamiento de las órdenes mendicantes en las ciudades contribuyó a redefinir modelos de comportamiento social y religioso, pues supieron atraer nuevos grupos sociales, en especial la oligarquía, a su pastoral, lo que se tradujo en más inhumaciones en los monasterios y la preservación de la memoria en las capillas, lo que contribuyó a la autoidentificación del grupo oligárquico con una misma religiosidad.

El propósito de esta reseña ha sido realizar una reflexión crítica sobre las sociedades urbanas y la construcción de las identidades urbanas peninsulares medievales a partir de los estudios incluidos en las monografías coordinadas por José María Monsalvo Antón y José Antonio Jara Fuente. Gracias a los diversos casos analizados en ambos libros, hemos podido apreciar la riqueza de las culturas y las identidades políticas de las sociedades urbanas peninsulares, así como la complejidad de los fenómenos observados y la necesidad de emprender futuros estudios que tengan en cuenta la variedad regional, ya no solo a escala peninsular, sino también europea, tarea a la que animamos, desde estas líneas, a ambos coordinadores, pues las tradiciones historiográficas nacionales de los diversos

20 Halbwachs, Maurice. La memoria colectiva. Zaragoza: Prensas Universitarias de Zaragoza, 2004. Burke, Peter. Formas de historia cultural. Madrid: Alianza Editorial, 2011, p. 66. 
JESÚS ÁNGEL SOLÓRZANO TELECHEA

LA IDENTIDAD URBANA Y LA HISTORIA SOCIAL DE LA POLÍTICA EN EL MUNDO URBANO ESPAÑOL Y PORTUGUÉS EN LA BAJA EDAD MEDIA

países europeos se han venido desarrollando excesivamente independientes y se impone la necesidad de estudios hechos desde una perspectiva comparada, como han sido los casos que nos han ocupado en esta reseña, y transnacional.

\section{REFERENCIAS BIBLIOGRÁFICAS}

Boucheron, Patrick y Offenstadt, Nicolas (eds.). L'espace public au Moyen Âge. Débats autour de Jürgen Habermas. Paris: Presses Universitaires de France, 2011.

Boucheron, Patrick y Ruiz Gómez, Francisco (coords.). Modelos culturales y normas sociales al final de la Edad Media. Cuenca: Casa de Velázquez, Ediciones de la Universidad de CastillaLa Mancha, 2009.

Bourdieu, Pierre. Bosquejo de una teoría de la práctica. Buenos Aires: Prometeo, 2012.

Bourdieu, Pierre. Razones prácticas. Sobre la teoría de la acción. Barcelona: Anagrama, 1997.

Brubaker, Rogers. Ethnicity without Groups. Cambridge: Harvard University Press, 2004.

Burke, Peter. «The language of orders in Early Modern Europe». En Bush, Michael L. (ed.). Social orders and social classes in Europe since 1500: studies in social stratification. London: Longman, 1992, pp. 1-12.

Burke, Peter. Formas de historia cultural. Madrid: Alianza Editorial, 2011.

Crossley, Nick y Roberts, John Michael (eds.). After Habermas: new perspectives on the Public Sphere. Oxford: Wiley-Blackwell, 2004.

Dumolyn, Jan. «Political communication and political power in the Middle Ages: a conceptual journey». Edad Media, 2012, vol. 13, pp. 33-55.

Dumolyn, Jan; Haemers, Jelle; Oliva Herrer, Hipólito Rafael; Challet, Vincent (eds.). The voices of the People in Late Medieval Europe. Turnhout: Brepols, 2014.

Foronda, François y Carrasco Manchado, Ana Isabel (dirs.). El contrato politico en la Corona de Castilla. Cultura y sociedad politica entre los siglos X al XVI. Madrid: Dykinson, 2008.

García Fernández, Ernesto. "Las cofradías de mercaderes, mareantes y pescadores vascas en la Edad Media». En Arízaga Bolumburu, Beatriz y Solórzano Telechea, Jesús Ángel (eds.). Ciudades y villas portuarias del Atlántico en la Edad Media. Logrońo: Instituto de Estudios Riojanos, 2005, pp. 257-294.

GiLli, Patrick. «Aux sources de l'espace politique: techniques électorales et pratiques délibératives dans les cités italiennes (XII ${ }^{\mathrm{e}}$-XIV ${ }^{\mathrm{e}}$ siècles)». En Boucheron, Patrick y Offenstadt, Nicolas (eds.). L'espace public au Moyen Âge. Débats autour de Jürgen Habermas. Paris: Presses Universitaires de France, 2011, pp. 229-247.

Habermas, Jürgen. Historia y critica de la opinión pública. La transformación estructural de la vida pública. Barcelona: Gustavo Gili, 1981.

Habermas, Jürgen. The Structural Transformation of the Public Sphere. Cambridge: The MIT Press, 1989.

Halbwachs, Maurice. La memoria colectiva. Zaragoza: Prensas Universitarias de Zaragoza, 2004.

Huddy, Leonie. «From Social to Political Identity: A Critical Examination of Social Identity Theory». Political Psychology, 2001, vol. 22/1, pp. 127-156.

IzQUIERDo BENITO, Ricardo. «Los conflictos socio-religiosos en las ciudades medievales castellanas». En Solórzano Telechea, Jesús Ángel y Arízaga Bolumburu, Beatriz (eds.). La convivencia en las ciudades medievales. Logrońo: Instituto de Estudios Riojanos, 2008, pp. 81-111.

Jansen, Harry. The construction of an urban past. Narrative and system in urban history. Oxford: Berg, 2001. 
JESÚS ÁNGEL SOLÓRZANO TELECHEA

Jara Fuente, José Antonio (coord.). Ante su identidad. La ciudad hispánica en la Baja Edad Media. Cuenca: Ediciones de la Universidad de Castilla-La Mancha, 2013.

Jara Fuente, José Antonio. «Sobre el concejo cerrado. Asamblearismo y participación política en las ciudades castellanas de la Baja Edad Media». Studia Historica. Historia Medieval, 1999, vol. 17, pp. 113-136.

Kieser, A. "Organizacional, Institucional and Societal Evolution: Medieval Craft Guilds and the Genesis of Formal Organizations». Administrative Science Quarterly, 1989, vol. 34/4, pp. 540-564.

Liddy, Christian D. and Haemers, Jelle. «Popular politics in the late medieval town: York and Bruges». English Historical Review, 2013, vol. 128, pp. 771-805.

LIDDY, Christian D. «Bill casting and political communication: A public sphere in late medieval English towns?». En Solórzano Telechea, Jesús Ángel y Arízaga Bolumburu, Beatriz (eds.). La gobernanza de la ciudad europea en la Edad Media. Logrońo: Instituto de Estudios Riojanos, 2011, pp. 447-461.

Liddy, Christian D. «Urban Enclosure Riots: Risings of the Commons in English Towns, 14801525». Past and Present, 2015, vol. 226, pp. 41-77.

Monsalvo Antón, José M. a (ed.). Sociedades urbanas y culturas políticas en la Baja Edad Media castellana. Salamanca: Ediciones Universidad de Salamanca, 2013.

Monsalvo Antón, José María. «Ideario sociopolítico y valores estamentales de los pecheros abulenses y salmantinos (ss. XIII-Xv)». Hispania. Revista Española de Historia, 2011, vol. LXXI, n. ${ }^{\circ}$ 238, pp. 325-362.

Monsalvo Antón, José María. "Solidaridades de oficio y estructuras de poder en las ciudades castellanas de la Meseta durante los siglos XIII al xv (aproximación al papel político del corporativismo artesanal)». En VACA, Ángel (ed.). El trabajo en la Historia. Salamanca: Ediciones Universidad de Salamanca, 1996, pp. 39-90.

Naegle, Gisela y SolórZano TelecheA, Jesús Ángel. «Geschlechter und Zünfte, prinçipales und común. Städtische Konflikte in Kastilien und dem spätmittelalterlichen Reich». Zeitschrift für Historische Forschung, 2014, vol. 41/4, pp. 561-618.

Najemy, John M. Corporatism and Consensus in Florentine Electoral Politics, 1280-1400. Chapel Hill: University of North Carolina Press, 1982.

NiEto Soria, José Manuel. «Three models of monarchy in fifteenth-century Castile». En Hoppenbrouwers, Peter; Janse, Antheun y Stein, Robert (eds.). Power and Persuasion. Essays on the Art of State Building in Honour of W. P. Blockmans. Turnhout: Brepols, 2010, pp. 85-102.

OrMroD, W. Mark. «Murmur, clamour and noise: Voicing complaint and remedy in petitions to the English crown, c. 1300-c. 1460». En Ormrod, W. Mark; Dodd, Gwilym y Musson, Anthony (eds.). Medieval Petitions: Grace and Grievance. York/Woodbridge: York Medieval Press, 2009, pp. 135-155.

Ormrod, W. Mark. Political life in Late Medieval England, 1300-1450. Basingstoke: Macmillan, 1995.

PÉneAu, Corinne (ed.). Élections et pouvoirs politiques du vII au XVII siècle. Bordeaux: Éditions Bière, 2008.

Prost, Antoine. Doce lecciones sobre la historia. Madrid: Cátedra, 2001.

Rigaudière, Albert. "Voter dans les villes de France au Moyen Âge (XIII ${ }^{\mathrm{e}}-\mathrm{XV}^{\mathrm{e}}$ s.)». Comptes-rendus des Séances de l'Académie des Inscriptions et Belles-Lettres, 2000, vol. 144/4, pp. 1439-1471.

Schneider, Reinhard y Zimmermann, Harald (dirs.). Wablen und Wählen im Mittelalter. Sigmaringen: Thorbecke, 1990. 
JESÚS ÁNGEL SOLÓRZANO TELECHEA

LA IDENTIDAD URBANA Y LA HISTORIA SOCIAL DE LA POLÍTICA EN EL MUNDO URBANO ESPAÑOL Y PORTUGUÉS EN LA BAJA EDAD MEDIA

Solórzano Telechea, Jesús Ángel y Haemers, Jelle. «Los grupos populares en las ciudades de la Europa medieval: reflexiones en torno a un concepto de historia social». En Solórzano Telechea, Jesús Ángel; Arízaga Bolumburu, Beatriz y Haemers, Jelle (eds.). Los grupos populares en la ciudad medieval europea. Logroño: Instituto de Estudios Riojanos, 2014, pp. 17-49.

Solórzano Telechea, Jesús Ángel. «Elites urbanas y construcción del poder concejil en las Cuatro Villas de la Costa de la Mar (siglos XiII-Xv)». En Arízaga Bolumburu, Beatriz y Solórzano Telechea, Jesús Ángel (eds.). Ciudades y villas portuarias del Atlántico en la Edad Media. Logrońo: Instituto de Estudios Riojanos, 2005, pp. 187-230.

Solórzano Telechea, Jesús Ángel. «La aparición y consolidación de la acción política del Común en las villas portuarias del Cantábrico en la Baja Edad Media». En Gentes de mar en la ciudad atlántica medieval. Logroño: Instituto de Estudios Riojanos, 2012, pp. 295 -312.

Solórzano Telechea, Jesús Ángel. «Protestas del común y cambio político en las villas portuarias de la España atlántica a finales de la Edad Media». En Oliva Herrer, Hipólito R.; Challet, Vincent; Dumolyn, Jan y Carmona Ruiz, M. a Antonia (eds.). La comunidad medieval como esfera pública. Sevilla: Universidad de Sevilla, 2014, pp. 45-72.

Solórzano Telechea, Jesús Ángel. "The politics of the urban commons in Northern Atlantic Spain in the Later Middle Ages». Urban History, 2014, vol. 41/2, pp. 83-204.

TRIO, Paul. «Les confréries comme expression de solidarité et de conscience urbaine aux PaysBas à la fin du Moyen Âge». En Brand, Hanno; Monnet, Pierre y Staub, Martial (eds.). Memoria, communitas, civitas. Memoire et conscience urbaines en Occident à la fin du Moyen Âge. Ostfildern: Thorbecke, 2003, pp. 131-141.

Val Valdivieso, María Isabel del. "La identidad urbana al final de la Edad Media». Anales de Historia Medieval de la Europa Atlántica, 2006, vol. 1, pp. 5-28.

Watts, John. "The Pressure of the Public on Later Medieval Politics». En Clark, Linda and Carpenter, Christine (eds.). The Fifteenth Century IV. Political Culture in Late Medieval Britain. Woodbridge: Boydell \& Brewer, 2004, pp. 159-180.

WatTs, John. The Making of Polities: Europe, 1300-1500. Cambridge: Cambridge University Press, 2009. 
